\title{
Priorización de problemas en las agendas legislativas autonómicas: instituciones y preferencias políticas
}

\author{
Anna M. Palau \\ Universidad de Barcelona \\ apalau@ub.edu \\ Laura Chaqués \\ Universidad de Barcelona \\ laurachaques@ub.edu \\ Luz M. Muñoz \\ Universidad de Barcelona \\ luzmunozma@ub.edu
}

\author{
LLuís Medir \\ Universidad de Barcelona \\ Iluismedir@ub.edu \\ Ferran Davesa \\ Universidad de Barcelona \\ fdavesa@ub.edu \\ Mariel Julio \\ Universidad de Barcelona \\ marieljulio@ub.edu
}

\begin{abstract}
Resumen
Este artículo analiza la agenda legislativa de cuatro Comunidades Autónomas -Andalucía, Cataluña, Galicia y el País Vasco-desde 1982 hasta 2007. El objetivo es explicar hasta qué punto los cambios en la priorización de problemas están relacionados con factores institucionales, como los cambios en el marco competencial o el proceso de europeización, o con factores políticos, como las preferencias de los partidos políticos. El análisis demuestra que a partir de los años noventa se inicia un proceso creciente de heterogeneidad entre las agendas autonómicas, y que este proceso no puede explicarse únicamente a partir de la distribución formal de competencias entre Estado y CCAA. La delegación de poder en favor de la Unión Europea no se ha traducido tampoco en una mayor homogeneidad de las agendas legislativas, ni siquiera en aquellos sectores más europeizados. El contexto institucional limita la capacidad de los gobiernos para regular sobre cuestiones concretas, pero las preferencias de los partidos son un factor importante para entender por qué existen similitudes o diferencias entre las agendas autonómicas.
\end{abstract}

Palabras clave Agenda legislativa, priorización de problemas públicos, Comunidades Autónomas, europeización, preferencias políticas.

\section{Issue prioritization in regional legislative agendas: institutions and political preferences}

\begin{abstract}
This article analyzes the legislative agenda of four regional governments - Andalusia, Catalonia, Galicia and the Basque Country-from 1982 to 2007. The goal is to explain to what extent changes in the prioritization of issues are related to institutional factors, such as changes in the distribution of competences and Europeanization, or political factors, like party preferences. The analysis illustrates that from the early nineties regional governments are increasingly paying attention to different issues, and that this process can not only be explained by taking into account the formal distribution of competences between central and regional governments. The delegation of power to the European Union does not contribute either to an increasing convergence of regional legislative agendas, not even for those issues more Europeanized. The institutional context constrains government's capacity to regulate specific issues, but party preferences are important to understand why there are similarities or differences among regional agendas.
\end{abstract}




\section{INTRODUCCIÓN ${ }^{1}$}

En este artículo se analiza la dinámica de la agenda legislativa en cuatro Comunidades Autónomas (CCAA) -Andalucía, Cataluña, Galicia y el País Vasco- desde los años ochenta hasta 2007. Los problemas sobre los que legislan estas cuatro CCAA son especialmente similares en los años ochenta, cuando una parte importante de la actividad legislativa se centra en la definición de instituciones autonómicas básicas, como las normas de funcionamiento de la administración pública o la definición de las relaciones de poder entre gobierno autonómico y gobierno local, así como algunos aspectos relativos a la construcción del Estado de bienestar, como la educación. A partir de los años noventa estos temas van perdiendo relevancia en favor de otros problemas relativos al Estado de bienestar, el medio ambiente, la política familiar, o la igualdad de género, con importantes diferencias entre CCAA.

La correlación entre las agendas legislativas se reduce de forma gradual a partir de los años noventa, incrementándose las diferencias en cuanto a los temas que captan más la atención en cada una de estas cuatro CCAA. En este artículo argumentamos que estos cambios en la agenda legislativa están relacionados con factores institucionales, como la distribución formal de competencias entre niveles de gobierno; y también con factores políticos, como las preferencias de los partidos políticos en el gobierno. Tal y como ponen de manifiesto diferentes estudios sobre federalismo (Requejo y Caminal, 2010; Linz y Stepan, 2006), la definición de un modelo de distribución territorial del poder de carácter cuasi-federal, asimétrico y abierto impone por un lado límites importantes sobre qué temas puede legislar cada CCAA, y al mismo tiempo establece una vía para modificar estos límites a partir de la negociación política.

El hecho que los asuntos económicos ocupen una parte importante en la agenda legislativa vasca desde principios de los ochenta se explica en gran parte por la existencia del concierto económico. Del mismo modo, en el tema de educación, la reforma de los Estatutos de Autonomía y la consecuente redefinición de las competencias en esta materia explica, en parte, que la primera ley autonómica sobre educación general -al margen de la educación universitaria- se apruebe en Andalucía en 2007 y en Cataluña en 2009. Estos límites relativos al marco competencial también se ven afectados por la delegación de poder "hacia arriba", en favor de instituciones supranacionales, que influyen sobre la priorización de problemas en la agenda legislativa española (Morata, 1992; Colomer, 1995; Closa, 2001). El hecho que problemas como el medio ambiente capten una parte importante de la agenda legislativa autonómica a partir de mediados de los noventa se explica en parte por el proceso de europeización y la consolidación gradual de una forma de gobierno multinivel (Aguilar, 1996).

$1 \quad$ Glosario de siglas de partidos o formaciones políticas que aparecen en el texto: ICV-IU (Iniciativa per Catalunya Verds-Izquierda Unida); ERC (Esquerra Republicana de Catalunya); PSOE (Partido Socialista Obrero Español; PP (Partido Popular) y PSC (Partit dels Socialistes de Catalunya). 
De todas formas, tal como se argumenta en este artículo, el proceso de europeización no genera una mayor convergencia en las agendas legislativas autonómicas. Las agendas legislativas de las cuatro comunidades son cada vez más diferentes, y en este proceso la influencia de la Unión Europea (UE) es marginal, lo que a su vez pone de manifiesto el papel central del ejecutivo español en el proceso de europeización. Los resultados de esta investigación también muestran la relevancia de las preferencias de los partidos para explicar el cambio en las agendas legislativas. La correlación entre las agendas legislativas de Andalucía y Cataluña aumenta de forma significativa a partir de 2003, cuando coinciden partidos socialistas en el gobierno de Andalucía y Cataluña (en coalición con ICV-IU y ERC) generando una tendencia hacia una mayor homogeneidad en la agenda legislativa de ambas Comunidades. En este sentido, estos resultados complementan en parte algunos de los análisis previos sobre las agendas legislativas de las CCAA como el realizado por Porras (2002) sobre las agendas legislativas autonómicas en España.

Las cuatro Comunidades estudiadas comparten una serie de características de índole institucional y política que hacen especialmente interesante su comparación. De acuerdo con la Constitución Española y los diferentes Estatutos de Autonomía, Andalucía, Cataluña, Galicia y el País Vasco siguen una vía rápida para acceder a la autonomía, y tienen un nivel competencial superior al resto de las CCAA, asumiendo en algunos casos una jurisdicción especial sobre determinadas cuestiones como la lengua (gallego, vasco y catalán), el Código Civil (Cataluña y País Vasco), y el régimen fiscal (el País Vasco y Navarra). Asimismo, son CCAA con una clara voluntad de autogobierno y es de subrayar su hecho diferencial respecto al resto de CCAA, lo que especialmente se manifiesta en el caso del País Vasco y Cataluña.

El artículo se estructura de la siguiente forma. En primer lugar se define el contexto teórico y las hipótesis de investigación. En segundo lugar se explica la metodología utilizada, y a continuación se describe la evolución de las agendas legislativas de las cuatro CCAA, a lo largo del tiempo y entre sectores de actividad. La última parte del artículo analiza hasta qué punto la creciente heterogeneidad entre las agendas legislativas autonómicas puede explicarse a través de los cambios en el contexto institucional y las preferencias de los partidos políticos.

\section{CONTEXTO TEÓRICO}

El marco competencial es un elemento básico en la definición del nivel de autonomía política, establece cuáles son las reglas del juego que regulan las relaciones de poder entre niveles de gobierno e impone restricciones importantes tanto sobre los problemas que pueden legislarse, como sobre el alcance de la legislación (Steinmo et al., 1992; Hall y Taylor, 1996). La Constitución Española define un modelo de distribución territorial del poder de carácter asimétrico y abierto que implica, por una parte, que existan diferencias importantes en cuanto a qué temas puede legislar cada CCAA -como los hechos diferenciales-, y por otra, que la distribución de competencias esté 
sometida a una negociación permanente entre los gobiernos nacional y autonómico (Aja, 2003; Requejo y Caminal, 2010).

Tal como muestra el gráfico 1, se han producido tres grandes etapas de regionalización. La primera etapa se produce en los años ochenta, como respuesta formal a los principios establecidos en la Constitución, los Estatutos de Autonomía y también algunos acuerdos bilaterales adoptados durante este período (Aja, 2003). La segunda etapa se produce a mediados de la década de 1990, como resultado de un proceso contradictorio de negociación. Por un lado, los dos principales partidos políticos nacionales, el PSOE y el PP, llegan a un acuerdo para delegar competencias políticas a las CCAA no históricas sobre cuestiones relativas al bienestar. Por otro lado, los gobiernos minoritarios del PSOE (1993-1996) y el PP (1996-2000) llegan a acuerdos bilaterales con algunas CCAA históricas, principalmente Cataluña y en cierta medida el País Vasco, orientados a aumentar su nivel de autonomía política en un rango más amplio de cuestiones.

\section{GRÁFICO 1}

Evolución de los decretos de transferencia de competencias a las CCAA

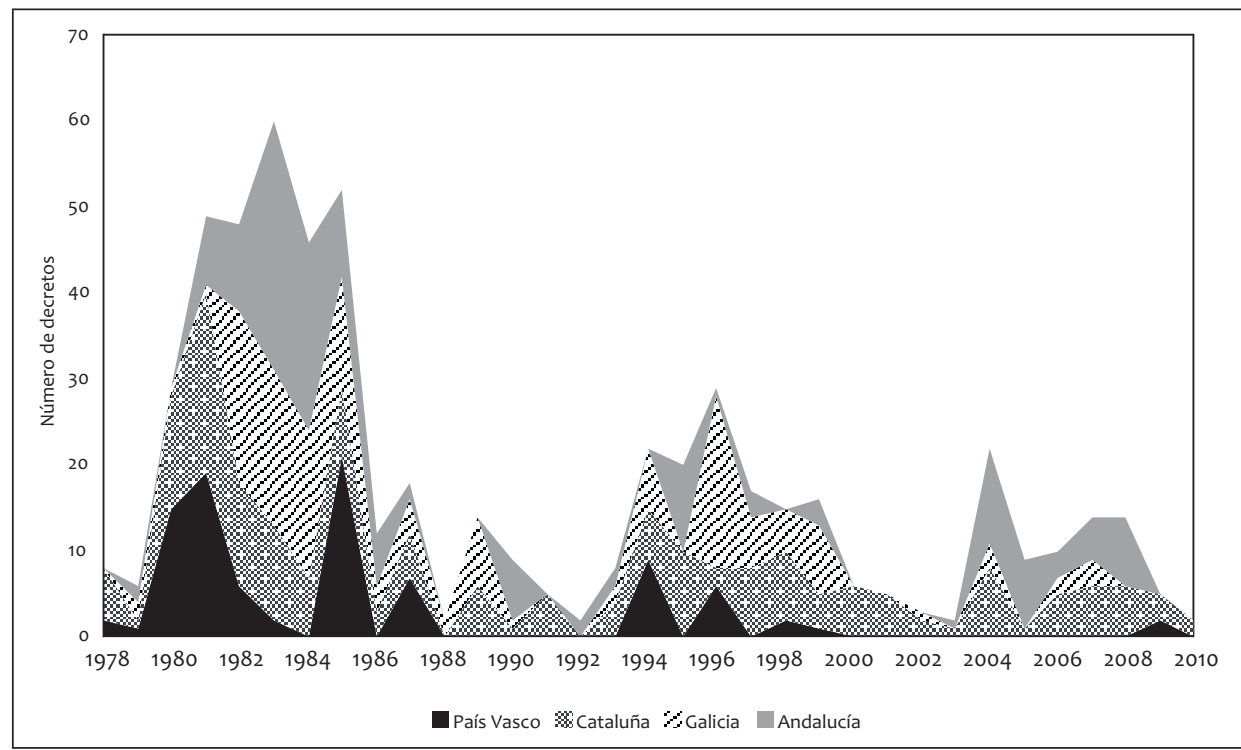

Fuente: Elaboración propia a partir de Iberlex (<http://www. boe.es/aeboe/consultas/bases_datos/iberlex. php>).

Por último, una tercera etapa de descentralización política se produce desde 2004 hasta la actualidad, bajo el gobierno de minoría de José Luís Rodríguez Zapatero, y se orienta principalmente a reformar los Estatutos de Autonomía, adaptándolos a las nuevas condiciones políticas, económicas y sociales. Porras (2002) argumenta 108 que los cambios en el marco competencial son un factor importante a partir del cual 
las CCAA ejercen potestad normativa propia, aunque más que un factor causal inmediato deberían definirse como una ventana de oportunidad política a partir de la cual las CCAA deciden sobre qué problemas debe legislarse, estableciendo prioridades distintas en función de sus preferencias. Siguiendo este argumento, en este artículo analizamos hasta qué punto existe correspondencia entre este proceso de traspaso de competencias hacia las CCAA y la creciente heterogeneidad de las agendas legislativas. En este sentido, esperamos que las agendas legislativas difieran cada vez más como consecuencia de este proceso de delegación gradual de competencias, a partir del cual cada una de las Comunidades históricas gana nuevas parcelas de poder sobre asuntos que hasta ese momento no son de su competencia.

Este proceso de creciente delegación de poder hacia las CCAA se produce de forma paralela al proceso de europeización que se inicia en 1986 con la entrada en la Comunidad Económica Europea (CEE). A partir de ese momento, los cambios en la lista de problemas que son objeto de atención por parte de los gobernantes están condicionados por el compromiso que asume España, tras la firma del Tratado de adhesión, a introducir a nivel nacional el "acervo comunitario", incluyendo las directivas, decisiones o reglamentos aprobados por las instituciones comunitarias (Morata, 1992; Colomer, 1995; Closa, 2001). En consecuencia, la definición de la agenda legislativa en España se produce, desde mediados de los ochenta, en un contexto multinivel en el que hasta tres niveles de gobierno participan en el proceso de elaboración de políticas.

La Unión Europea facilita la transferencia de políticas entre países y entre niveles de gobierno, favoreciendo procesos de convergencia política y la consiguiente homogenización de políticas entre Estados miembros, especialmente en aquellos temas vinculados con el mercado único y el medio ambiente (DiMaggio y Powell, 1983; Dolowitz y Marsh, 1996; Holzinger y Knill, 2005; Palau y Chaqués, 2011). Esto disminuye de forma significativa la autonomía del Estado, pero también la de las CCAA en el ámbito de sus respectivas competencias. El hecho que la UE tenga capacidad para definir los estándares medioambientales que deben respetar las políticas de residuos de los Estados miembros, o para establecer límites a las posibilidades de financiar la actividad agraria, condiciona la forma en que los Estados y las CCAA abordan la regulación de estas materias.

Análisis como el de Brouard et al. (2011) ponen de manifiesto la creciente europeización de la agenda legislativa de los países miembros de la UE, especialmente en ámbitos como la agricultura o el medio ambiente, donde la jurisdicción comunitaria tiene más competencias, aun cuando pueden distinguirse diferencias significativas entre países². La mayoría de estos análisis se limitan al ámbito estatal, dejando en un

2 En el caso de España, Palau y Chaqués (2011) demuestran la creciente europeización de la agenda legislativa española, de forma que desde la entrada de España en la CEE en 1986 hasta 2006, un 35\% de la legislación española hace referencia directa a alguna norma comunitaria vinculante, si bien en la última década en torno al $50 \%$ de las leyes que se aprueban tienen contenido europeo. Por el contrario en países 
segundo término el impacto de la UE sobre la agenda legislativa regional, con algunas excepciones (Borghetto y Franchino, 2010). En España, las CCAA han aumentado de forma progresiva su participación en la toma de decisiones y en el proceso de elaboración de políticas en Europa (ver Börzel, 2002; Closa, 2001; Montilla, 2005; Gunther y Montero, 2009), pero existe poca evidencia empírica sobre cómo las CCAA participan en la fase descendente, de implementación de la normativa comunitaria. En este sentido, tomando como referencia los trabajos de Ordóñez (1995), Montilla (2005) y/o Palau y Chaqués (2011), se analiza hasta qué punto las leyes aprobadas por las CCAA responden a la necesidad de implementar normativa comunitaria. En consecuencia, esperamos que en aquellos sectores más europeizados, donde la regulación debe ajustarse a los parámetros establecidos por la Unión Europea, exista una mayor convergencia entre las agendas legislativas autonómicas.

La consolidación de un sistema de gobierno multinivel es un factor necesario pero no suficiente para explicar la dinámica de las agendas legislativas. La distribución formal de competencias entre niveles de gobierno no nos explica por qué algunas CCAA como Cataluña y el País Vasco deciden crear una policía regional en los años ochenta, o por qué Andalucía tiene un papel principal en la regulación de cuestiones morales, como la investigación con células madre o la eutanasia pasiva, mientras otras CCAA nunca han regulado estas cuestiones. Los factores institucionales explican en parte los cambios en la agenda legislativa del Estado y de las CCAA, pero los cambios en la priorización de problemas son también el resultado de las preferencias de los partidos políticos y de la voluntad de sus líderes para introducir cambios en la agenda y responder a cambios en el entorno (Jones y Baumgartner, 2005). La relación entre las preferencias de los partidos y la priorización de problemas se ha analizado ampliamente desde diferentes perspectivas (Budge y Hofferbert, 1990; GreenPedersen, 2006; Schmidt, 1996). Análisis como los de Boix (2000) o Blais et al. (1993) se centran en si existe una mayor tendencia de los partidos de izquierda a centrarse en cuestiones que impliquen más intervención por parte del Estado; o si por el contrario los partidos de derechas se centran más en políticas que fomenten la desregulación y el libre mercado (Blais et al., 1993).

Desde otra perspectiva, el party mandate theory (Budge y Hofferbert, 1990; Klingemann et al., 1994) sugiere que los partidos políticos compiten dando especial relevancia a aquellos problemas "que les pertenecen" o "que les son propios", dejando en un segundo plano las posiciones ideológicas que los partidos pudiesen tomar respecto a los mismos (Klingeman et al., 1994; Green-Pedersen, 2006). Los electores en general consideran que algunos partidos son más competentes para gestionar determinados asuntos ( $y$ en consecuencia consideran también que pueden solucionarlos de forma más efectiva); de modo que los partidos responden a las preferencias de sus electores dando relevancia a aquellos problemas que potencialmente pueden generar más beneficios en términos electorales. En este sentido, se considera que los

11 como Francia este porcentaje de europeización es menor, alcanzando sólo el 14\% del total de leyes aproba-
das entre 1986 y 2006. 
partidos políticos tienen preferencias definidas de forma clara, y que sus líderes dan especial importancia a los valores y a la ideología de su partido, dejando en un segundo plano cualquier otra preferencia, como su propio éxito como líderes (Baumgartner y Mahoney, 2008). De acuerdo con esta argumentación, esperamos que cuando en distintas CCAA gobierne un mismo partido político o con ideología similar, las agendas legislativas regionales sean más parecidas. A continuación se explica la metodología utilizada para la comprobación de las hipótesis de investigación y en las siguientes secciones se desarrolla el análisis sobre la evolución de las agendas legislativas, teniendo en cuenta la importancia de factores institucionales y las preferencias de los partidos políticos.

\section{METOdOLOGÍA}

Con el fin de analizar las variaciones entre las agendas de las CCAA y entre niveles de gobierno, en este artículo nos centramos en el estudio de una sola forma de actividad política: la producción de leyes. La agenda legislativa se define como el conjunto de temas sobre los que se aprueban normas con rango de ley por los parlamentos nacionales y autonómicos (Brouard et al., 2009; Adler y Wilkerson, 2008). El estudio de las leyes ofrece una información importante sobre el nivel de atención que reciben distintos problemas, pero es también un análisis limitado en cuanto no es el único mecanismo a través del cual los políticos prestan atención a los asuntos que consideran prioritarios (Chaqués et al., 2008; Chaqués y Palau, 2011). A modo de ejemplo, y para el caso de la europeización, en España el 90\% de las directivas se trasponen a través de legislación secundaria (Palau y Chaqués, 2011), tendencia que según algunos estudios (Ordóñez, 1995; Montilla 2005) todavía es más acusada en el ámbito autonómico ${ }^{3}$. Esto supone una limitación de partida que obviamente deberá tenerse en cuenta a la hora de formular conclusiones.

Nuestro análisis se realiza a partir de bases de datos creadas por el Grupo de Análisis Comparado de la Agenda Política en España (<http://www.ub.edu/spanishpolicyagendas >) siguiendo la metodología del Comparative Policy Agendas Project (<http:// www.comparativeagendas.org >) (Baumgartner y Jones 1993; Jones y Baumgartner, 2005). Cada ley ha sido codificada de acuerdo con un sistema universal de codificación basado en 19 categorías (cuadro 1), y 247 subcategorías. Este sistema de codificación, desarrollado por primera vez por Baumgartner y Jones en los Estados Unidos, se ha adaptado a las características del sistema político español introduciendo algunas modificaciones para tener en cuenta elementos que no tienen equivalente en ese país, como cuestiones relacionadas con el sistema nacional de salud pública o el terrorismo de ETA.

Tal como muestra el cuadro 1, las 19 categorías originales se han fusionado en cuatro grandes bloques: (1) economía; (2) Estado de bienestar; (3) medio ambiente y

3 De acuerdo con Montilla (2005: 95), en 2002 se aprueban 543 normas autonómicas en España vinculadas al Derecho comunitario, de las que sólo 33 tienen rango legal. 
(4) funciones básicas del Estado. Las bases de datos utilizadas incluyen todas las leyes aprobadas por los parlamentos autonómicos de las cuatro CCAA estudiadas y se comparan con las leyes aprobadas por el parlamento español con el fin de explicar la distribución de competencias entre niveles de gobierno, y comparar la evolución de la agenda legislativa autonómica con la española. Los datos para el caso de España están disponibles desde 1977, en el caso de Cataluña y el País Vasco desde 1980, y en el caso de Andalucía y Galicia desde 1982, una vez se aprueban los Estatutos de Autonomía. En consecuencia, el análisis comparativo abarca el período comprendido entre 1982 y 2007 . En conjunto, se analizan un total de 2.911 leyes -1511 aprobadas a nivel nacional, 526 en Cataluña, 299 en Galicia, 318 en el País Vasco y 257 en Andalucía-.

\section{CUADRO 1}

Principales códigos del Comparative Policy Agendas Project

\begin{tabular}{|c|c|}
\hline \multirow{8}{*}{ Economía } & 1. Macroeconomía \\
\hline & 4. Agricultura \\
\hline & 5. Trabajo \\
\hline & 8. Energía \\
\hline & 10. Transporte \\
\hline & 15. Industria y comercio \\
\hline & 17. Ciencia y tecnología \\
\hline & 18. Comercio exterior \\
\hline \multirow{4}{*}{ Estado de bienestar } & 3. Salud \\
\hline & 6. Educación \\
\hline & 13. Política social \\
\hline & 14. Vivienda \\
\hline \multirow{2}{*}{ Medio ambiente } & 7. Medio ambiente \\
\hline & 21. Recursos naturales y gestión del agua \\
\hline \multirow{5}{*}{ Funciones básicas del Estado } & 12. Asuntos internos y justicia \\
\hline & 2. Derechos civiles \\
\hline & 16. Defensa \\
\hline & 19. Relaciones internacionales \\
\hline & 20. Gobierno y administración pública \\
\hline
\end{tabular}

Fuente: Elaboración propia a partir de la metodología del Comparative Policy Agendas Project.

Para el análisis de la europeización de las leyes se tiene en cuenta formas de europeización directas. Es decir, consideramos que una ley está europeizada si está total o parcialmente definida por un acto legislativo europeo vinculante: decisión, directiva, reglamento, disposición del Tribunal de Justicia Europeo o Tratado. Las formas indirectas de europeización, como referencias indirectas o "soft law", no han sido consideradas ${ }^{4}$. Por último, para analizar la influencia de los factores políticos e institucionales en

4 El procedimiento de codificación se ha basado en un sistema de codificación manual y una bús-

112 queda por palabras clave definidas por el Delors Myth Project (ver Brouard et al., 2011). 
las agendas legislativas, se han computado las correlaciones anuales entre las agendas regionales y entre las agendas regionales y la agenda estatal (variable dependiente) y se ha analizado su relación con el proceso de transferencia de competencias, el porcentaje de legislación europeizada, y las preferencias políticas-(variables independientes). Para el análisis cuantitativo se han utilizando tablas de contingencia, así como el estadístico Gamma para comprobar si las correlaciones son significativas y su magnitud 5 .

\section{COMPARACIÓN DE LAS AGENDAS LEGISLATIVAS}

El análisis de la producción legislativa en Andalucía, Cataluña, Galicia y el País Vasco indica que las autoridades regionales prestan atención a asuntos similares, pero con importantes variaciones a partir de la década de los noventa (gráfico 2 ). Como muestra la tabla 1, si tenemos en cuenta todos los asuntos y todo el período (1982-2007), las agendas regionales están moderadamente correlacionadas -la correlación media es de 0.32-. A partir de la década de los noventa la correlación anual media entre las agendas legislativas disminuye gradualmente y pasa de 0.5 en la década de los ochenta, a ser inferior a 0.2 (siempre significativa) a partir de la década de 2000. Estos datos ponen de manifiesto que las autoridades regionales cada vez prestan más atención a cuestiones diferentes, tendencia que se intensifica a partir del nuevo milenio (Chaqués y Palau, 2011).

\section{GRÁFICO 2}

Correlación anual entre las agendas legislativas autonómicas: problemas relativos al Estado de bienestar

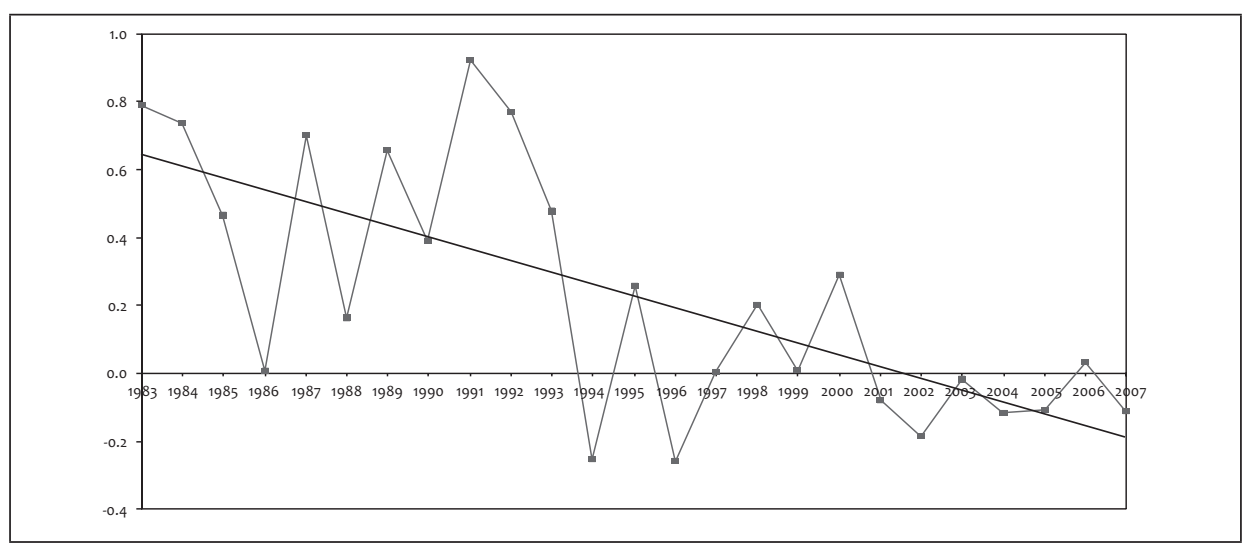

Fuente: Bases de datos del Grupo de Análisis Comparado de la Agenda Política en España (<http://www. ub.edu/spanishpolicyagendas>).

5 Para interpretar los coeficientes de correlación se utiliza la siguiente regla (Blomquist, 1981): el valor 0.00 indica que no hay relación, entre 0.01 y 0.09 indica una relación insignificante; entre 0.10 y 0.19 una relación baja; entre 0.20 y 0.35 una relación moderada; entre 0.36 y 0.49 una relación sustancial y 0.5 o superior una relación muy fuerte. 
TABLA 1

Correlaciones entre las agendas legislativas (1980-2008)

\begin{tabular}{|l|c|c|c|c|c|}
\hline & Cataluña & País Vasco & Galicia & Andalucía & $\begin{array}{c}\text { Gobierno } \\
\text { central }\end{array}$ \\
\hline Cataluña & 1 & $.247^{* *}$ & $.335^{* *}$ & $.364^{* *}$ & $.340^{* *}$ \\
\hline País Vasco & $.247^{* *}$ & 1 & $.333^{* *}$ & $.301^{* *}$ & $.378^{* *}$ \\
\hline Galicia & $.335^{* *}$ & $.333^{* *}$ & 1 & $.343^{* *}$ & $.366^{* *}$ \\
\hline Andalucía & $.364^{* *}$ & $.301^{* *}$ & $.343^{* *}$ & 1 & $.379^{* *}$ \\
\hline Gobierno central & $.340^{* *}$ & $.378^{* *}$ & $.366^{* *}$ & $.379^{* *}$ & 1 \\
\hline
\end{tabular}

** La correlación es significativa al nivel de 0.01 .

Fuente: Bases de datos del “Grupo de Análisis Comparado de la Agenda Política en España” (<http://www. ub.edu/spanishpolicyagendas >).

El análisis de los porcentajes de atención ofrece más información sobre estas diferencias a lo largo del tiempo entre CCAA y niveles de gobierno (tabla 2). En primer lugar, la mayoría de las leyes autonómicas están relacionadas con cuestiones económicas, y especialmente en el País Vasco (48\%), dado el hecho diferencial con el resto de CCAA en materia de política fiscal. En segundo lugar, la regulación de funciones básicas del Estado capta una parte importante de atención en las agendas legislativas (alrededor de un 30\%) con diferencias importantes entre problemas. Obviamente, en aquellos temas en los que el Estado tiene competencia exclusiva, las CCAA tienen un papel inexistente (como en defensa), o marginal como en el caso de las relaciones exteriores, en el que se aprueban algunas leyes en relación a la ayuda exterior y la política de cooperación internacional. En el caso de interior y justicia, Cataluña dedica casi el mismo porcentaje de atención que el Gobierno español, un 9,2\% de la agenda legislativa, casi el doble que el resto de CCAA. En este sentido, el Parlamento catalán aprobó 28 leyes relacionadas con el derecho civil, el 54\% de las leyes en materia de interior y justicia, básicamente porque la Constitución Española le reconoce una capacidad competencial de creación y desarrollo específica sobre esta cuestión.

En tercer lugar, la tabla 3 pone de manifiesto la elevada descentralización política en aquellas cuestiones relativas al Estado de bienestar. En general, cada CCAA dedica aproximadamente el $23 \%$ de la agenda legislativa a la regulación de cuestiones de bienestar, frente al 9,7\% de la agenda legislativa nacional. La mayoría de estas leyes están relacionadas con la educación primaria y secundaria y las universidades (10\%), con algunas diferencias entre CCAA. El número de leyes sobre universidades es superior en Cataluña y Andalucía en comparación con otras CCAA (De Miguel, 2002), mientras que la atención a la educación primaria y secundaria es mayor en el País Vasco, debido a la regulación de las ikastolas (escuelas de primaria y secundaria Vasca) (tabla 3). Por último, la atención a las cuestiones de salud es especialmente importante en Andalucía (5\%), que tiene un papel protagonista en la regulación de la biotecnología a partir de la década de los noventa, mientras que en Cataluña y el País Vasco la atención a los problemas de salud disminuye a lo largo del tiempo y capta sólo el $2.5 \%$

114 de la agenda legislativa. En cuarto lugar, existen importantes diferencias en la regula- 
ción de problemas medioambientales entre CCAA. Cataluña es el Gobierno regional que legisla más sobre medio ambiente -más del 10\% de las leyes aprobadas en Cataluña están relacionadas con este asunto- en contraste con el País Vasco, que sólo le dedica el $3 \%$ de la agenda legislativa. El resto de CCAA dedican entre el 6 y el $7 \%$ de la agenda legislativa al medio ambiente, porcentaje similar a la agenda legislativa española (6.7\%), a pesar de que en muchas cuestiones medioambientales las CCAA tienen competencia exclusiva.

TABLA 2

Porcentajes de atención por área (\% de leyes aprobadas)

\begin{tabular}{|c|c|c|c|c|c|}
\hline & Galicia & País Vasco & Andalucía & Cataluña & $\begin{array}{c}\text { Gobierno } \\
\text { central }\end{array}$ \\
\hline \multicolumn{6}{|c|}{ Economía, I+D y política industrial } \\
\hline Economía & 15,8 & 24,2 & 19,3 & 12,2 & 17,7 \\
\hline Agricultura & 9,4 & 3,0 & 1,6 & 3,6 & 4,4 \\
\hline Trabajo & 1,7 & 3,0 & 2,0 & 1,4 & 6,1 \\
\hline Energía & 0,7 & 1,3 & 0,8 & 0,4 & 1,8 \\
\hline Transporte & 2,0 & 3,7 & 2,8 & 4,3 & 5,8 \\
\hline Industria & 11,1 & 10,4 & 11,0 & 11,7 & 13,4 \\
\hline Investigación y desarrollo & 1,7 & 2,3 & 6,7 & 4,1 & 2,9 \\
\hline Total & 42,4 & 47,9 & 44,1 & 37,7 & 52,1 \\
\hline \multicolumn{6}{|l|}{ Estado de bienestar } \\
\hline Salud & 3,7 & 2,3 & 5,5 & 2,2 & 2,7 \\
\hline Educación & 9,1 & 9,7 & 11,4 & 9,7 & 4,5 \\
\hline Política social & 4,7 & 5,0 & 3,9 & 5,2 & 1,1 \\
\hline Vivienda & 5,1 & 5,7 & 2,4 & 4,8 & 1,5 \\
\hline Total & 22,6 & 22,7 & 23,2 & 21,9 & 9,7 \\
\hline \multicolumn{6}{|l|}{ Medio ambiente } \\
\hline $\begin{array}{l}\text { Recursos naturales y } \\
\text { gestión del agua }\end{array}$ & 2,4 & 1,3 & 3,9 & 3,6 & 4,0 \\
\hline Medio ambiente & 5,1 & 1,7 & 2,4 & 7,2 & 2,7 \\
\hline Total & 7,4 & 3,0 & 6,3 & 10,8 & 6,7 \\
\hline \multicolumn{6}{|l|}{ Funciones básicas del Estado } \\
\hline Derechos & 3,0 & 3,0 & 2,4 & 1,8 & 3,1 \\
\hline $\begin{array}{l}\text { Asuntos internos y } \\
\text { justicia }\end{array}$ & 4,4 & 3,0 & 3,5 & 9,2 & 10,0 \\
\hline Política exterior & 0,3 & 1,3 & 0,8 & 0,7 & 3,5 \\
\hline Gobierno & 19,5 & 18,8 & 19,7 & 18,0 & 10,9 \\
\hline Defensa & 0,0 & 0,0 & 0,0 & 0,0 & 4,1 \\
\hline Total & 27,5 & 26,1 & 26,4 & 29,6 & 31,5 \\
\hline
\end{tabular}

Fuente: Bases de datos del Grupo de Análisis Comparado de la Agenda Política en España (<http://www. ub.edu/spanishpolicyagendas >). 
TABLA 3

Regulación de la educación y la cultura

\begin{tabular}{|l|c|c|c|c|c|}
\hline & Universidades & $\begin{array}{c}\text { Educación } \\
\text { primaria y } \\
\text { secundaria }\end{array}$ & Cultura & Lengua & Otros \\
\hline País Vasco & 22,6 & 35,5 & 23 & 3,2 & 16,2 \\
\hline Cataluña & 35,2 & 9,3 & 20,4 & 7,4 & 28 \\
\hline Galicia & 19,2 & 15,4 & 27 & 7,7 & 31 \\
\hline Andalucía & 34,5 & 3,4 & 31 & 0 & 31 \\
\hline Estado & 28,2 & 9,9 & 12,7 & 1,4 & 47,8 \\
\hline
\end{tabular}

Fuente: Bases de datos del Grupo de Análisis Comparado de la Agenda Política en España (<http://www. ub.edu/spanishpolicyagendas >).

El gráfico 3 muestra la evolución de la regulación de los asuntos de gobierno en las últimas décadas. Como era de esperar, la regulación es especialmente importante durante la década de los ochenta y principios de los noventa, cuando las CCAA definen los principios y las instituciones básicas del Estado de bienestar autonómico (Subirats y Gallego, 2002). En este período, aproximadamente el $24 \%$ de la agenda legislativa a nivel regional y el $14,2 \%$ a nivel nacional se dedica a la regulación de instituciones básicas, las relaciones intergubernamentales, la organización y la financiación de los partidos políticos, las elecciones, y/o el funcionamiento de la administración pública. La atención sobre estas cuestiones disminuye durante la década de los noventa, y sólo aumenta de nuevo durante el nuevo milenio en las CCAA que reforman sus Estatutos de Autonomía (Cataluña en 2006 y Andalucía en 2007). Lo mismo ocurre en el caso de algunas cuestiones relacionadas con el Estado de bienestar y especialmente en el caso de la educación y la cultura.

Por el contrario, tal y como muestra el gráfico 4, la mayoría de las leyes relativas a la regulación de derechos se aprueban en el nuevo milenio. En la década de los ochenta sólo el 1,5\% de la agenda legislativa autonómica se dedica a regular estos temas, aumentando hasta el 5,4\% después de 2000. Estas leyes regulan cuestiones como la igualdad de género, los derechos del paciente, la protección de datos y las políticas de accesibilidad. Un análisis detallado de esta legislación muestra cómo Andalucía y Cataluña están liderando un proceso de cambio en estas materias, especialmente en aquellas vinculadas con la regulación de aspectos morales (Chaqués y Palau, 2011).

La atención a las cuestiones económicas aumenta en todas las CCAA, excepto en el País Vasco, sobre todo una vez que se pone en marcha la reforma fiscal de 1997. Este es especialmente el caso de Cataluña, que aprovecha la oportunidad que le brinda esta reforma para aumentar su nivel de autonomía política. A modo de ejemplo, Cataluña es la única Comunidad Autónoma que crea en 2007, una vez reformado su Estatuto de Autonomía, una Oficina de Impuestos (Agencia Tributaria) responsable 116 de la gestión, liquidación e inspección de los impuestos nacionales (transferidos) y 


\section{GRÁFICO 3}

Regulación de los asuntos de gobierno

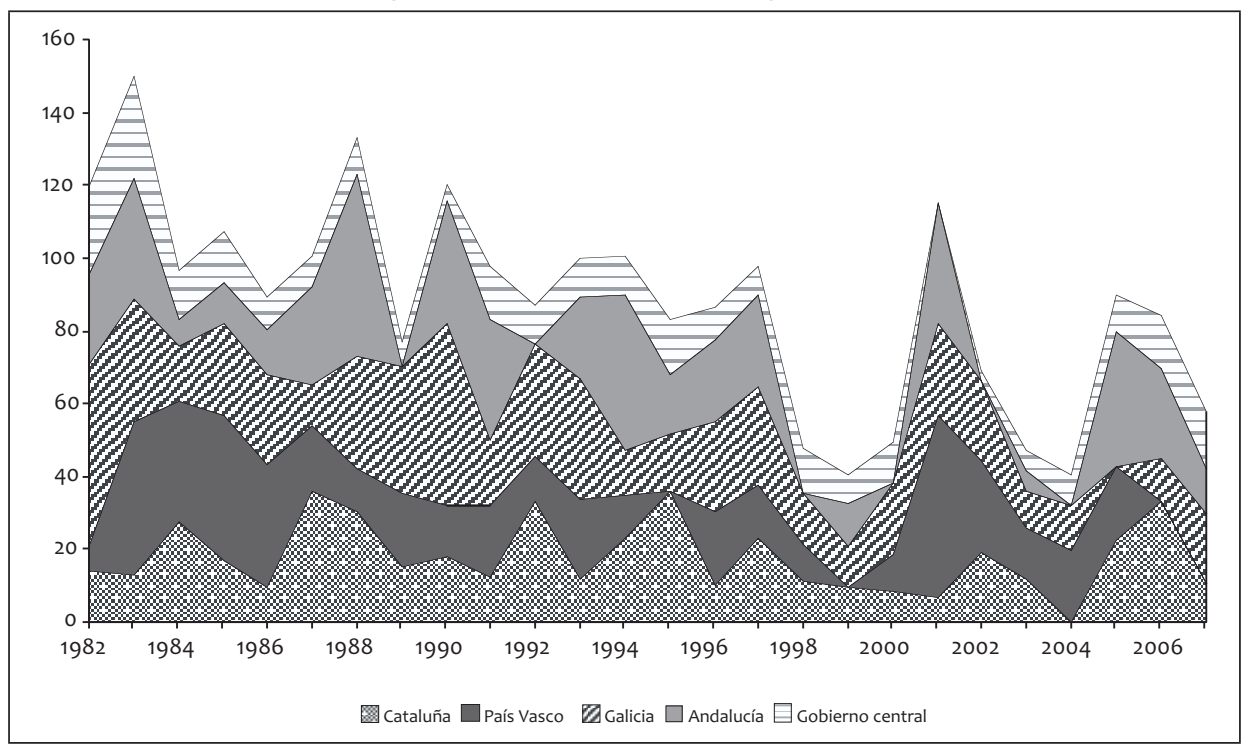

Fuente: Bases de datos del “Grupo de Análisis Comparado de la Agenda Política en España” <http://www. ub.edu/spanishpolicyagendas>

\section{GRÁFICO 4}

\section{Regulación de los derechos}

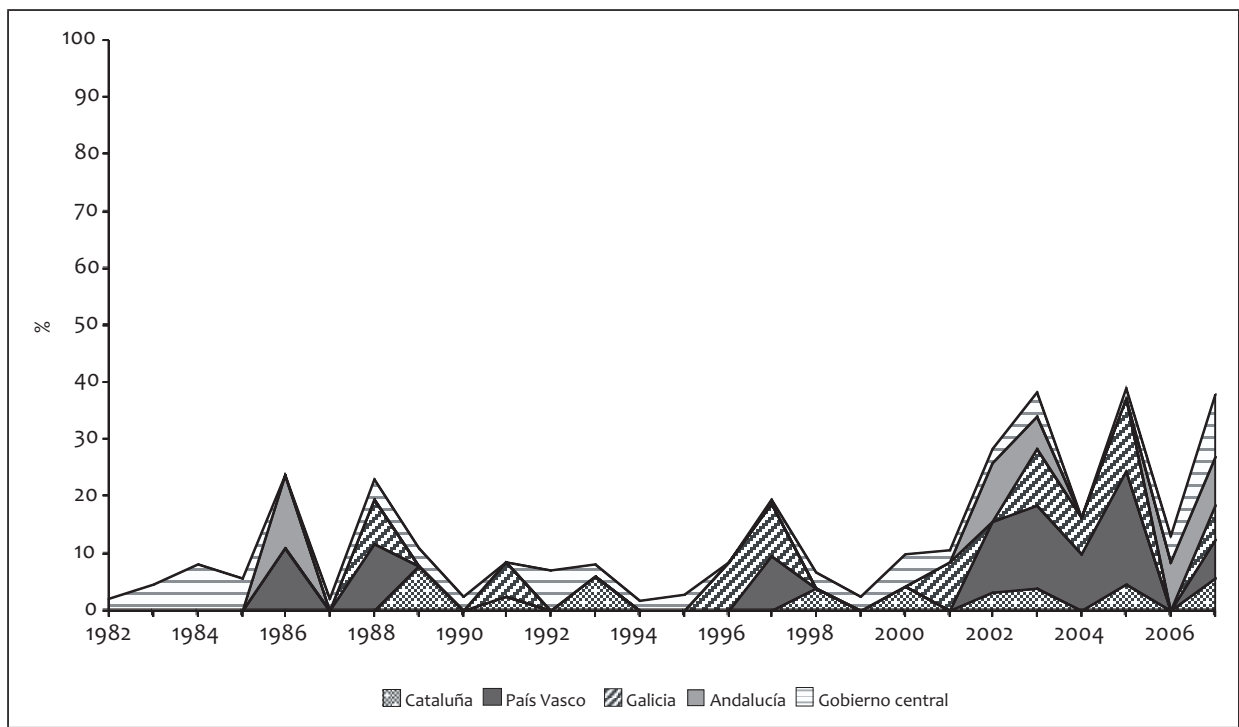

Fuente: Bases de datos del Grupo de Análisis Comparado de la Agenda Política en España (<http://www. ub.edu/spanishpolicyagendas >). 
regionales. La creciente atención prestada por las autoridades regionales a las cuestiones económicas contrasta con la disminución de la atención que el gobierno central presta a esta cuestión: a principios de los noventa la economía capta el 19,7\% de la agenda legislativa nacional, mientras que en el nuevo milenio baja al 14,9\%. Este es un ejemplo del juego de suma cero que, según Gunther y Montero (2009: 9), ha caracterizado las relaciones centro-periferia en España durante años, con una cantidad fija de poder político dentro del Estado, de modo que si los poderes regionales ganan poder, el gobierno central lo pierde.

La reforma fiscal de 1997 es identificada por Hooghe et al. (2010) como un factor primordial para determinar el grado de autonomía política de las CCAA. De acuerdo con su índice, la autonomía política aumenta en todas las CCAA tras esta reforma, reduciéndose las diferencias respecto al País Vasco y Navarra. Una cuestión importante es hasta qué punto esta mayor autonomía política se ha traducido en una fragmentación creciente de la agenda legislativa de las CCAA. Esto es, hasta qué punto el hecho de que éstas tengan más autonomía fiscal facilita que un mayor número de problemas entren en la agenda legislativa generando una mayor fragmentación. En este sentido, el gráfico 5 muestra la evolución del índice de Herfindahl para cada agenda legislativa desde principios de los ochenta hasta la actualidad. Este índice se define como un indicador de competencia, originariamente entre empresas rivales en un mismo sector económico, que aplicado al estudio de la agenda permite conocer el grado de concentración o fragmentación de la misma. Su versión normalizada resulta de la suma de los porcentajes de atención al cuadrado en cada uno de los códigos, y oscila desde una situación hipotética de competencia perfecta (0) al monopolio (1). Una puntuación por debajo de 0,1 indica generalmente una baja concentración de la agenda, entre 0,1 y 0,18 una concentración moderada, y por encima de 0,18 una concentración de la agenda elevada.

Los resultados muestran cómo el número de temas que captan la atención del legislador es siempre mayor en Cataluña que en el resto de CCAA, especialmente en relación con Galicia y Andalucía. Asimismo, en el caso de Cataluña, el País Vasco y Galicia hay una tendencia moderada hacia una mayor fragmentación desde finales de los ochenta hasta la actualidad -en el caso de Cataluña el nivel medio de fragmentación en la década de los ochenta es de 0,14, mientras que desde 1997 hasta la actualidad el nivel de fragmentación disminuye hasta alcanzar un promedio de 0,07-. Estos resultados muestran la disposición de estas CCAA (con la excepción de Andalucía) a aumentar su autonomía política, y adoptar decisiones por ley sobre un conjunto cada vez más amplio de problemas. Sin embargo, el hecho de que la agenda legislativa del País Vasco también esté cada vez más fragmentada cuestiona el impacto de la reforma fiscal de la década de los noventa sobre la capacidad de la agenda autonómica.

Por último, el análisis de correlaciones y de los porcentajes anuales de atención muestran que los cambios en los niveles de atención a lo largo del tiempo, entre CCAA y entre niveles de gobierno, no pueden explicarse únicamente a partir de cam-

118 bios en el contexto institucional. Por ejemplo, el hecho que Andalucía y Cataluña de- 
diquen una mayor atención a la regulación de la I+D, sobre todo a partir de 2003, en comparación con el resto de CCAA, se explica a partir de las preferencias políticas de los partidos que gobiernan estas comunidades, y su voluntad de priorizar estas cuestiones. Del mismo modo, la creación de una policía regional en la década de 1980 es una de las prioridades del País Vasco y Cataluña, pero no del resto de las CCAA. La posibilidad reconocida en la Constitución española de establecer policías autonómicas abrió una ventana de oportunidad política que fue aprovechada por estas dos CCAA con el fin de consolidar su autogobierno y crear instituciones diferenciadas de las establecidas por el gobierno central. Para el caso del País Vasco, la creación de una policía regional en 1982 también se relaciona con la lucha contra el terrorismo de ETA. Por el contrario, este asunto sólo capta ligeramente la atención de los políticos en Galicia a mediados de 2000, mientras que en Andalucía pasa casi totalmente inadvertido. El siguiente apartado analiza hasta qué punto las diferencias entre las agendas legislativas a lo largo del tiempo pueden explicarse a partir de cambios en el contexto institucional, o en las preferencias de los partidos políticos.

\section{GRÁFICO 5}

\section{Fragmentación de las agendas legislativas autonómicas}

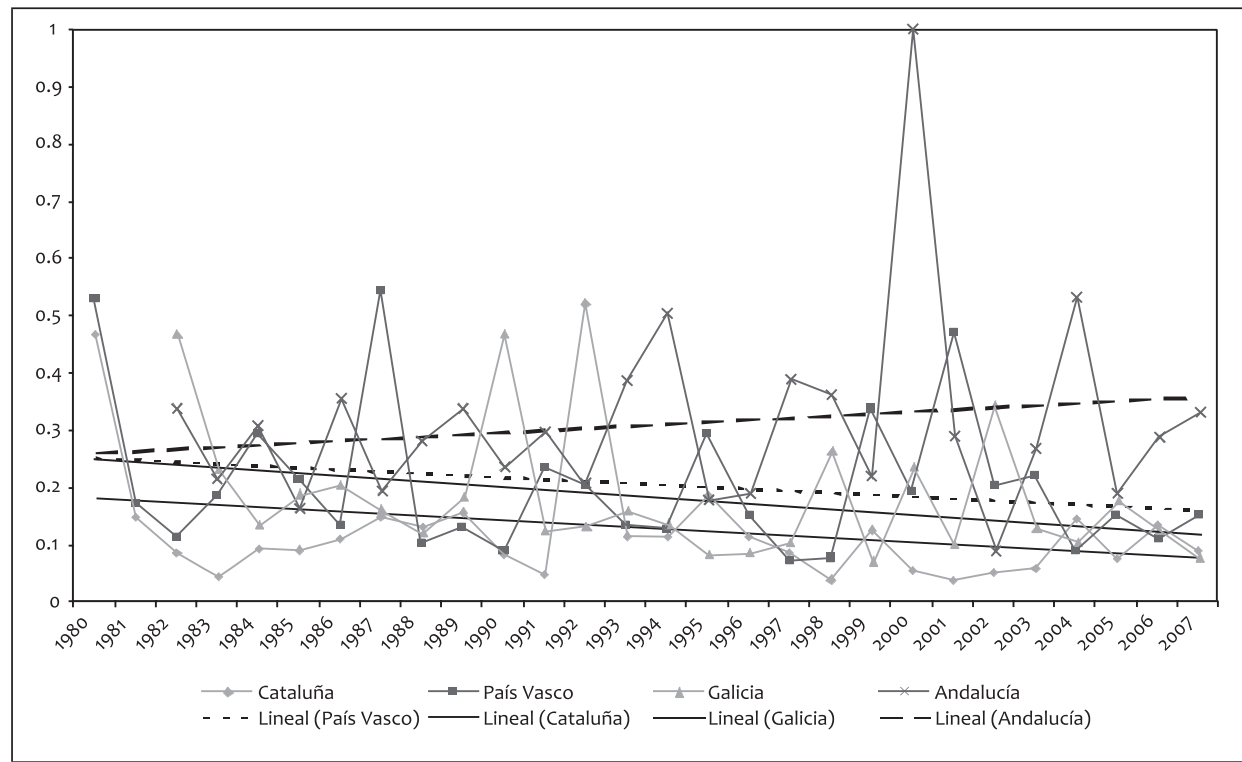

Fuente: Bases de datos del Grupo de Análisis Comparado de la Agenda Política en España (<http://www. ub.edu/spanishpolicyagendas >).

\section{INSTITUCIONES, CONVERGENCIA Y AGENDA LEGISLATIVA}

La primera cuestión que abordamos es hasta qué punto la delegación de poder “hacia arriba”, en favor de instituciones supranacionales, afecta a la dinámica de la 
agenda legislativa de las CCAA generando una mayor homogeneización en aquellos asuntos más europeizados. El análisis detallado de las leyes autonómicas y estatales muestra que la europeización de la actividad legislativa en España varía significativamente entre niveles de gobierno, entre sectores de actividad y a lo largo del tiempo. En primer lugar, la europeización afecta principalmente a la agenda legislativa del Estado, y sólo de forma marginal a la agenda legislativa de las CCAA. Un 35\% de las leyes aprobadas por el parlamento español entre 1986 y 2007 están total o parcialmente definidas por una norma comunitaria vinculante, sin embargo, tal como muestra el gráfico 6, el porcentaje de legislación europeizada ha aumentado de forma significativa a lo largo del tiempo hasta casi el 50\% en la última década (Palau y Chaqués, 2011).

\section{GRÁFICO 6}

Porcentaje de legislación europeizada: Comunidades Autónomas y Estado

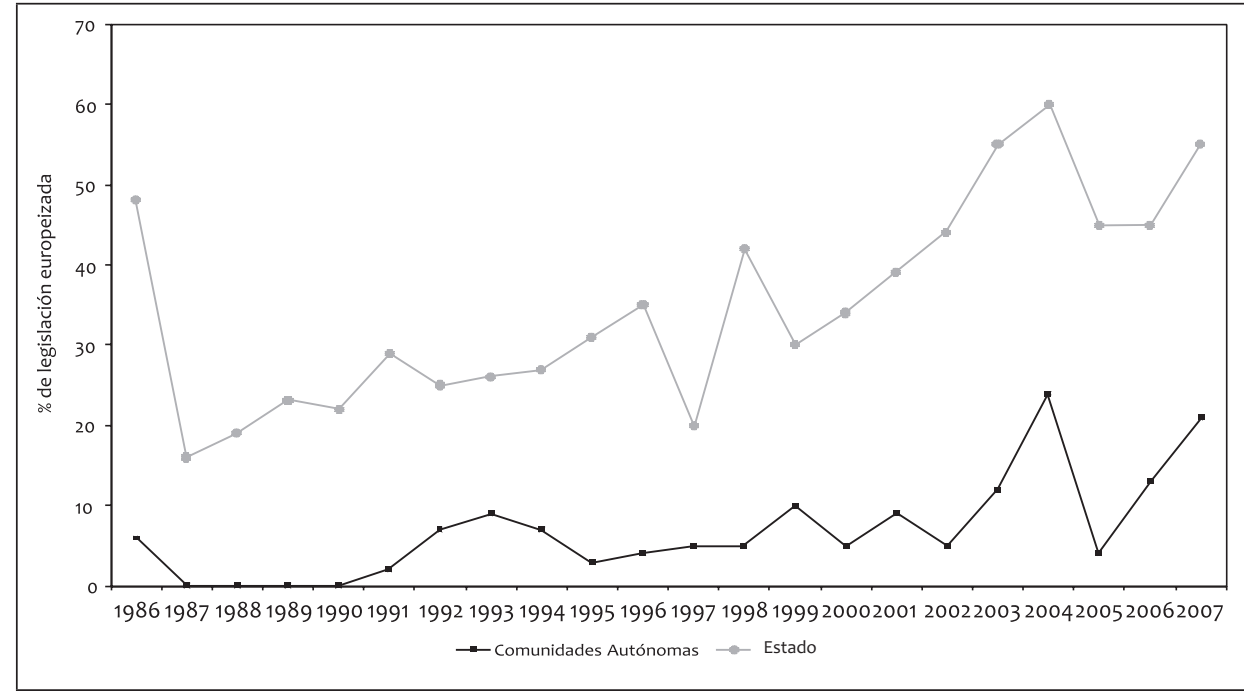

Fuente: Bases de datos del Grupo de Análisis Comparado de la Agenda Política en España (<http://www. ub.edu/spanishpolicyagendas>).

En el caso de las CCAA, la europeización de la agenda ha aumentado aunque en menor proporción. Entre 1986 y 1993 sólo un 3\% de las leyes que aprueban las CCAA estudiadas están europeizadas, porcentaje que aumenta hasta el $6 \%$ en los noventa y el $12 \%$ en el nuevo milenio. Si consideramos todo el período, sólo el $7 \%$ de leyes autonómicas están europeizadas, porcentaje muy inferior al de las leyes estatales. Galicia y Andalucía son las CCAA que tienen la agenda más europeizada (14 y $8 \%$ respectivamente). País Vasco tiene un 5\% de legislación europeizada y Cataluña sólo un 2\%. Estos datos confirman que es el gobierno central, y no las CCAA, quien asume el liderazgo en la fase descendente, de implementación de la normativa comunitaria, incluso en

120 áreas que están muy descentralizadas. 
Como muestra el gráfico 7, sectores como agricultura y medio ambiente, donde las CCAA tienen importantes competencias, son los más europeizados a nivel estatal -un 63\% del total de la legislación estatal en estos sectores está europeizada, mientras que a nivel regional la legislación con contenido europeo representa sólo el 25 y el 21\% respectivamente-. También existen diferencias importantes en otros ámbitos, como ciencia y tecnología ( $59 \%$ de europeización a nivel estatal frente a $5 \%$ a nivel regional), economía ( $56 \%$ frente $3.3 \%$ a nivel autonómico), energía (52\% y 20\%), o política industrial ( $50 \%$ y $9 \%$ ). Los niveles de europeización, como era de esperar, son menos elevados en sectores como justicia e interior (12\% y $6 \%$ ), y en aquellas cuestiones vinculadas con el Estado de bienestar, como la política social (25\% y $3 \%$ ), la salud (33\% y $3 \%$ ) o la educación ( $22 \%$ y $4 \%$ ). Un caso especial es la europeización en materia de derechos, dónde las CCAA tienen un porcentaje de europeización mayor que el Estado. Esto se debe a que casi un 40\% de la legislación autonómica en este ámbito hace referencia a la regulación de la igualdad de género, una política sobre la que la UE ha tenido un fuerte impacto y que entra en todas las agendas regionales siguiendo las directrices marcadas por las instituciones comunitarias (Delgado, 2011).

\section{GRÁFICO 7}

Porcentaje de legislación europeizada por sectores de actividad: Comunidades Autónomas y Estado

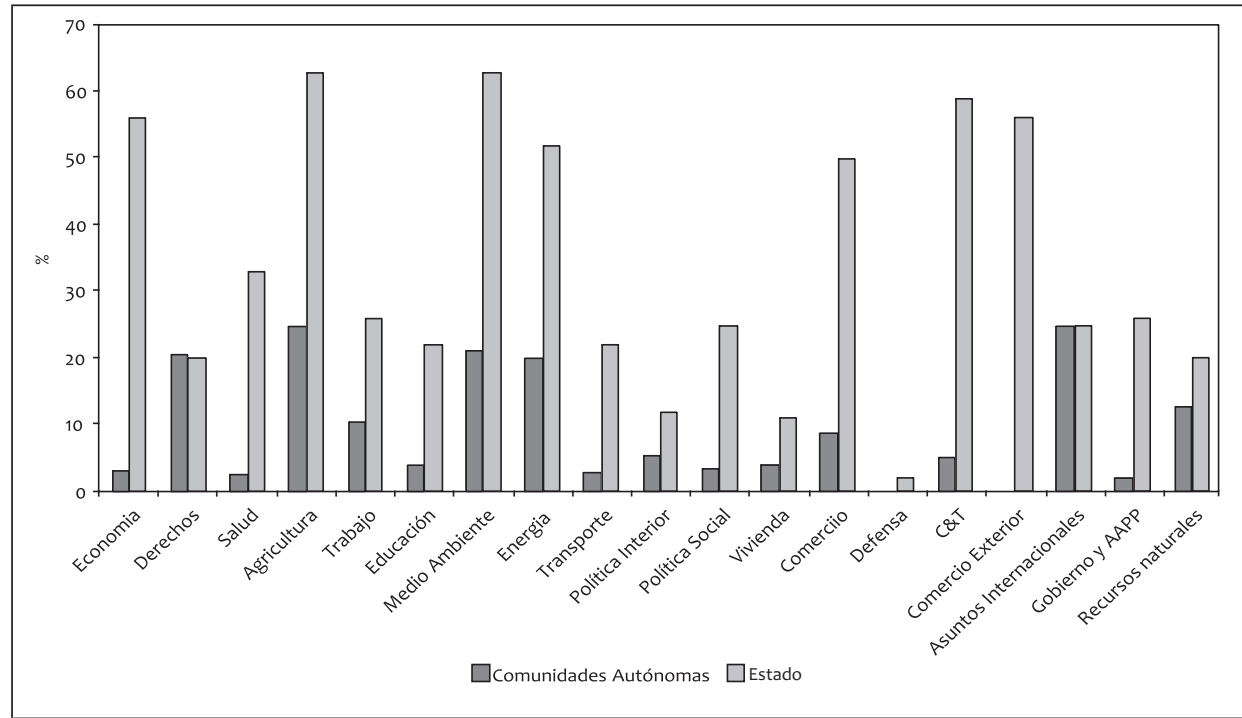

Fuente: Bases de datos del Grupo de Análisis Comparado de la Agenda Política en España (<http://www. ub.edu/spanishpolicyagendas $>$ ).

En definitiva, el mayor porcentaje de legislación europeizada a nivel nacional confirma el carácter centrípeto de la europeización, también en la fase descendente, así como las deficiencias del marco legislativo que regula en España la intervención autonómica en la incorporación de normativa comunitaria (Montilla, 2005). El mayor 
protagonismo del Estado se explica por la complejidad que representa en su momento la coincidencia en el tiempo de la construcción del Estado autonómico y la incorporación a la CEE; pero también por la ausencia de uniformidad competencial del Estado autonómico, en virtud de la cual el Estado asume el liderazgo para evitar deficiencias en la implementación que pudieran comprometer al Estado ante las instituciones europeas, garantizando la coordinación y la homogeneización en la interpretación del derecho comunitario a lo largo del territorio (Ordóñez, 1995; Montilla, 2005).

La cuestión que se plantea aquí es hasta qué punto este progresivo aumento de la europeización se ha traducido en un aumento de la convergencia entre agendas, especialmente en aquellos sectores donde la UE tiene mayores competencias. Si consideramos tanto la legislación autonómica como la estatal en materia económica, existe una relación positiva entre el porcentaje de legislación europeizada y la correlación anual entre agendas: a medida que aumenta el número de legislación europeizada las agendas son más parecidas (gráfico 8). No obstante, la correlación no es significativa y tal como muestra la tabla 4, si tenemos en cuenta todo el periodo y todos los sectores de actividad, no hay una relación significativa entre el aumento del porcentaje de legislación europeizada y las correlaciones anuales entre agendas. Es decir, no podemos aceptar la hipótesis de que a medida que aumenta el porcentaje de legislación europeizada, aumenta la correlación entre agendas, ni siquiera si tenemos sólo en cuenta aquellos sectores más europeizados.

\section{GRÁFICO 8}

Correlación anual entre agendas legislativas y porcentaje de legislación europeizada en economía

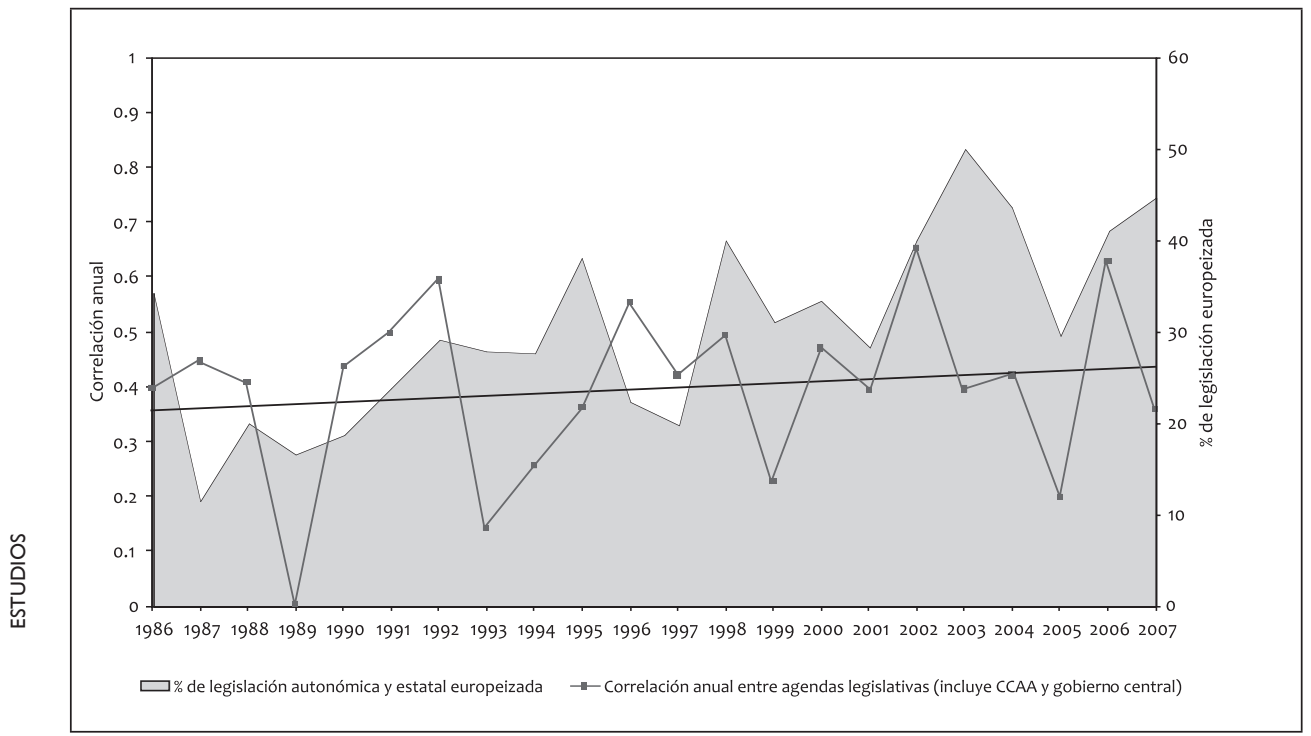

Fuente: Bases de datos del Grupo de Análisis Comparado de la Agenda Política en España (<http://www. ub.edu/spanishpolicyagendas>). 
TABLA 4

Impacto de la europeización en la correlación entre agendas legislativas

\begin{tabular}{|l|c|c|c|c|}
\hline \multirow{2}{*}{$\begin{array}{c}\text { Porcentaje de } \\
\text { correlaciones anuales* }\end{array}$} & Muy bajo & Bajo & Elevado & Muy elevado \\
\hline Muy bajas & 6,2 & 1,4 & 0 & 0 \\
\hline Bajas & 12,4 & 31,5 & 33,3 & 20 \\
\hline Elevadas & 37,6 & 30,1 & 38,1 & 50 \\
\hline Muy elevadas & 43,8 & 37 & 28,6 & 30 \\
\hline Gamma & \multicolumn{5}{|c|}{ No sign. } \\
\hline sig. & \multicolumn{5}{|c|}{-0.1} \\
\hline Interpretación & \multicolumn{5}{|c|}{} \\
\hline
\end{tabular}

* Las correlaciones se consideran muy bajas si están entre -1 y 0.25 ; bajas entre 0.26 y 0.50 , elevadas entre 0.51 y 0.75 y muy elevadas entre 0.76 y 1

** Se considera el porcentaje de europeización sobre el total de leyes aprobadas. El porcentaje de legislación europeizada se considera muy bajo si está entre el o y el $25 \%$ del total, bajo entre 26 y $50 \%$, elevado entre 51 y $75 \%$ y muy elevado entre 76 y $100 \%$.

Fuente: Bases de datos del Grupo de Análisis Comparado de la Agenda Política en España (<http://www. ub.edu/spanishpolicyagendas >).

Un ámbito que pone de manifiesto la compleja relación entre el contenido europeo de la agenda y la priorización de problemas es el medio ambiente. En este ámbito, la creciente europeización de la política no explica por qué se dan diferencias importantes en la regulación de esta cuestión a lo largo del tiempo, entre CCAA y niveles de gobierno. El elevado nivel de residuos industriales que se generan en Cataluña en comparación con el resto de CCAA -Cataluña genera el 25\% del total de residuos generados en España-, y la presión ejercida por movimientos cívicos como la Plataforma Cívica per la Reducció de Residus, explica que esta Comunidad Autónoma lidere en España la regulación en materia de residuos industriales y calidad del aire, adelantándose al resto de CCAA e incluso a la regulación estatal (Casademunt, 2001). La ley catalana de residuos de 1993 incorpora los altos niveles de exigencia ambiental establecidos por la Directiva 156/1991/CEE, mientras que el Estado, debido a la presión de sectores empresariales, incorpora esta normativa comunitaria cinco años más tarde, cuando ya había terminado el plazo fijado por las instituciones comunitarias para su transposición. Esto es importante porque pone de manifiesto que, si bien la UE tiene capacidad para definir el contenido de la regulación, especialmente en aquellas cuestiones relativas al mercado único y el medio ambiente, el Estado y en su caso las CCAA conservan cierto margen de maniobra para decidir el momento concreto en el que entran en la agenda: no se controla totalmente cómo se regula pero sí que pueden decidir hasta cierto punto cuándo se regula.

Otra cuestión es hasta qué punto el proceso de delegación "hacia abajo", es decir, el proceso de transferencia de competencias en favor de las CCAA, está relacio- 
nado con esta tendencia hacia una mayor heterogeneidad de las agendas legislativas. Dado el carácter flexible y abierto del modelo autonómico definido en la Constitución, el nivel competencial ha variado a lo largo del tiempo a través de procesos de delegación de competencias (definidos en los decretos de transferencia de competencias) a las CCAA. Como muestra el gráfico 9, la transferencia de competencias es especialmente importante en la década de los ochenta, lo que debe ser visto como una respuesta formal a los principios establecidos en la Constitución, los Estatutos de Autonomía y también algunos acuerdos bilaterales adoptados durante este período (Aja, 2003).

\section{GRÁFICO 9}

Correlación anual entre las agendas legislativas autonómicas y \% de transferencia de competencias a las CCAA

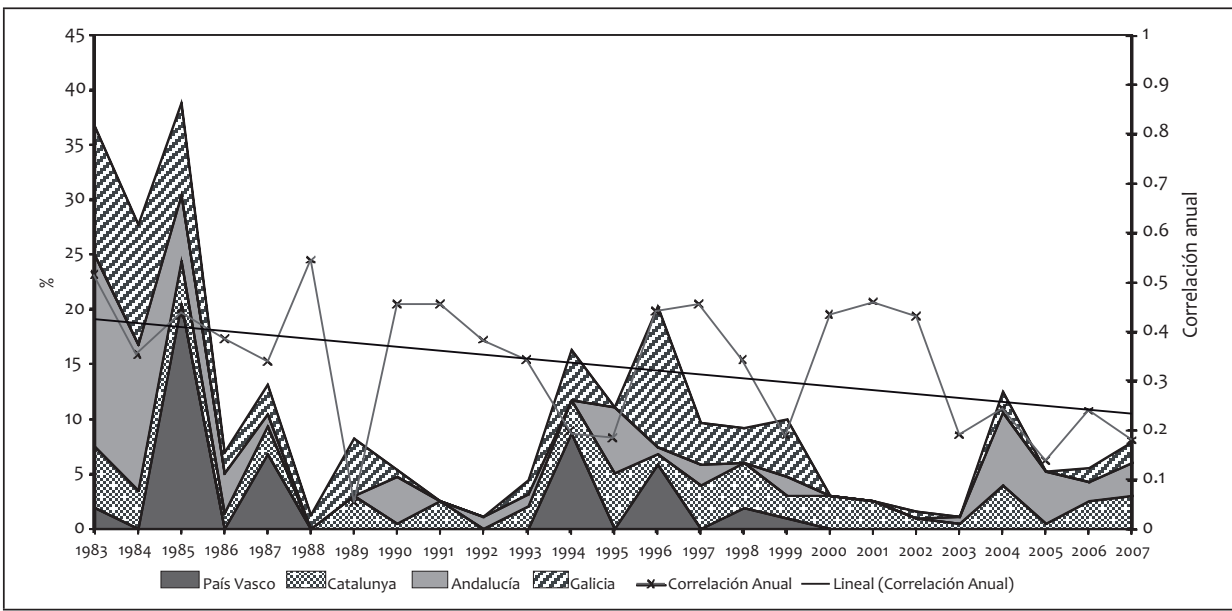

Fuente: Bases de datos del Grupo de Análisis Comparado de la Agenda Política en España (<http://www. ub.edu/spanishpolicyagendas>).

El gráfico 9 también pone de manifiesto que el proceso de delegación de competencias en favor de las CCAA está relacionado con la mayor convergencia entre las agendas legislativas a lo largo de los ochenta, pero no puede explicar por qué a partir de los noventa las agendas son cada vez más distintas. En la política educativa universitaria por ejemplo, la convergencia entre las agendas legislativas a lo largo de los ochenta ocurre una vez delegadas las principales competencias en esta materia. Después de la aprobación de la Ley de Reforma Universitaria (LRU) de 1983, se efectúan diversos traspasos competenciales a las CCAA con el objetivo de ejecutar tanto las previsiones de la LRU, como las del artículo 27 de la CE y distintas disposiciones estatutarias. Así pues, entre 1985 y 1987, se transfieren las competencias a todas las CCAA en materia de universidades, lo que permite a las CCAA crear nuevas universidades y legislar sobre determinados aspectos relativos a la gestión

124 universitaria, facilitando la creación de un mapa universitario propio. A partir de los 
años noventa, y a pesar de que el proceso de delegación competencial continua, la correlación no es significativa.

\section{PREFERENCIAS POLÍTICAS Y PRIORIZACIÓN DE PROBLEMAS}

Las CCAA deciden sobre qué asuntos debe legislarse en función de las limitaciones impuestas por el contexto institucional en el que actúan, pero también en función de sus preferencias políticas. Siguiendo este argumento, a continuación analizamos hasta qué punto las agendas legislativas se parecen más cuando el mismo partido político, o de ideología similar, gobierna en distintas comunidades autónomas: ¿Aumenta la similitud entre las agendas de Cataluña y Andalucía cuando los socialistas gobiernan en ambas Comunidades (2003-2008) ? ¿La semejanza entre las agendas de Cataluña y el País Vasco se incrementa cuando en ambas gobiernan partidos nacionalistas (1980-2003)? ¿Aumenta la correlación entre las agendas española y catalana tras la alternancia política en 2003? En primer lugar, como muestra la tabla 5 , las correlaciones anuales entre las agendas legislativas catalana y andaluza son mayores cuando los socialistas gobiernan en ambas CCAA. El porcentaje de correlaciones anuales superiores a 0,5 casi se triplica cuando los socialistas gobiernan en ambas CCAA (75\% de las correlaciones están por encima de 0.5). A modo de ejemplo, es en este periodo de liderazgo socialista cuando se crea en ambas CCAA una autoridad independiente -el Consejo Audiovisual-, responsable de la regulación de la política audiovisual (contenidos de televisión, la publicidad, las licencias audiovisuales, etc.); y cuando se aprueban de forma casi simultánea medidas de prevención y protección contra la violencia de género. En este sentido, cabe destacar que también en Galicia se aprueban medidas para erradicar la violencia de género cuando gobierna el Partido Socialista, lo que viene a corroborar la hipótesis de que las preferencias de los partidos políticos son importantes para entender los procesos de convergencia entre agendas.

En segundo lugar, las correlaciones anuales entre la agenda legislativa catalana y la del gobierno central son también más elevadas cuando coincide el partido político. El porcentaje de correlaciones superiores a 0.5 pasa del $19 \%$ cuando CIU gobierna en Cataluña, al 50\% cuando en Cataluña gobierna el PSC y en el gobierno central el PSOE (tabla 5). Un ejemplo de la similitud entre las agendas socialistas a nivel nacional y autonómico lo encontramos en la regulación de cuestiones relativas a la memoria histórica. En 2007, tanto el parlamento español como el catalán aprueban una ley sobre esta cuestión (Ley 52/2007 de la Memoria Histórica y Ley 13/2007 del Memorial Democrático) con el apoyo del resto de partidos políticos excepto del PP,

6 Para simplificar se refiere al gobierno de los socialista en Cataluña desde 2003, sabiendo que es un gobierno de coalición formado por PSC, ERC y ICV, y liderado por José Montilla.

7 Es interesante destacar que, a pesar de que el gobierno central tiene competencias para desarrollar la legislación básica sobre estos temas, no se regula una autoridad específica nacional responsable del control de la política audiovisual hasta 2008. 
que no había identificado nunca este tema como prioritario, y ERC, que no dio apoyo a la ley española por considerarla insuficiente en el reconocimiento de derechos. Cataluña es la única comunidad autónoma que ha regulado esta cuestión, en respuesta a las demandas ciudadanas pero también de acuerdo con las prioridades de los partidos políticos que conforman la coalición de gobierno desde 2003 a 2010 (PSC, ERC e ICV).

\section{TABLA 5}

Cambios en la correlación entre agendas legislativas

en función del partido político

\begin{tabular}{|l|c|c|c|c|c|c|c|c|}
\hline & \multicolumn{2}{|c|}{$\begin{array}{c}\text { Cataluña- } \\
\text { Andalucía }\end{array}$} & \multicolumn{2}{c|}{$\begin{array}{c}\text { Cataluña-País } \\
\text { Vasco }\end{array}$} & \multicolumn{2}{c|}{ Cataluña-Galicia } & \multicolumn{2}{c|}{$\begin{array}{c}\text { Cataluña- } \\
\text { Estado }\end{array}$} \\
\hline $\begin{array}{l}\text { Porcentaje de } \\
\begin{array}{l}\text { correlaciones } \\
\text { anuales* }\end{array}\end{array}$ & PSC & CIU & PSC & CIU & PSC & CIU & PSC & CIU \\
\hline Muy bajas & 25 & 42,9 & 75 & 38,1 & 25 & 33,3 & 25 & 38,1 \\
\hline Bajas & 0 & 28,6 & 25 & 52,4 & 50 & 28,6 & 25 & 42,9 \\
\hline Elevadas & 25 & 23,8 & 0 & 9,5 & 25 & 38,1 & 25 & 14,3 \\
\hline Muy elevadas & 50 & 4,8 & 0 & 0 & 0 & 0 & 25 & 4,8 \\
\hline Gamma & \multicolumn{2}{|c|}{-0.6} & \multicolumn{2}{|c|}{0.7} & \multicolumn{2}{c|}{0.05} & \multicolumn{2}{c|}{0.4} \\
\hline sig. & \multicolumn{2}{|c|}{0} & \multicolumn{2}{|c|}{0} & \multicolumn{2}{c|}{0.604} & \multicolumn{2}{c|}{0} \\
\hline Interpretación & $\begin{array}{c}\text { relación muy } \\
\text { fuerte }\end{array}$ & \multicolumn{2}{c|}{$\begin{array}{c}\text { relación muy } \\
\text { fuerte }\end{array}$} & \multicolumn{2}{c|}{ no sig. } & \multicolumn{2}{c|}{$\begin{array}{c}\text { relación } \\
\text { sustancial }\end{array}$} \\
\hline
\end{tabular}

* Las correlaciones se consideran muy bajas si están entre -1 y 0.25 ; bajas entre 0.26 y 0.50 , elevadas entre 0.51 y 0.75 y muy elevadas entre 0.76 y 1

Fuente: Bases de datos del Grupo de Análisis Comparado de la Agenda Política en España (<http://www. ub.edu/spanishpolicyagendas >).

En tercer lugar, la correlación anual entre la agenda catalana y la vasca es mayor cuando CIU y PNV están gobernando en ambas comunidades, que cuando los socialistas gobiernan en Cataluña y el PNV gobierna en el País Vasco (el porcentaje de correlaciones anuales superiores a 0,5 aumenta hasta el 9,5\% y el porcentaje de correlaciones muy bajas disminuye de 75 a 38,1\%) (tabla 5). Por ejemplo, existe convergencia en la regulación de las corporaciones de radio y televisión, así como en temas de política lingüística. La primera ley vasca de creación del ente público "Radio Televisión Vasca” se aprobó en mayo de 1982 (Ley 5/1982), regulando los principios de la corporación y sus contenidos, su estructura orgánica, los criterios de elección de sus miembros y los mecanismos de control parlamentario. Por su parte, Cataluña aprueba un año después una ley con una estructura y finalidades similares a la vasca (Ley 10/1983). También regulan de forma casi paralela el tema de la normalización lingüística, el País Vasco en 1982 y Cataluña en 1983, regulaciones que convergen en el interés por recuperar la lengua propia como signo de identidad. Otro ejemplo de convergencia es la

126 regulación del derecho civil foral, que se produce en ambos casos a mediados de los 
noventa, con el objetivo de ordenar, actualizar y diferenciar ambas legislaciones del derecho civil común.

\section{CONCLUSIONES}

Las agendas legislativas de las cuatro CCAA estudiadas -Andalucía, Cataluña, Galicia y el País Vasco- son cada vez más heterogéneas en cuanto a su contenido, y estas diferencias no se pueden explicar teniendo en cuenta únicamente factores institucionales, como la distribución de competencias entre niveles de gobierno, o hechos diferenciales establecidos en la Constitución Española y los Estatutos de Autonomía. Los asuntos que priorizan las CCAA son especialmente parecidos en los años ochenta, cuando se está llevando a cabo la construcción de las instituciones políticas autonómicas y el desarrollo de los pilares del Estado de bienestar. A partir de los noventa, una vez que se han sentado las bases del Estado autonómico tanto a nivel institucional como sustantivo, se producen cambios importantes en el patrón de priorización de problemas por parte de cada una de las CCAA, generando una creciente divergencia en el contenido de la agenda legislativa autonómica.

La creciente heterogeneidad de las agendas legislativas autonómicas pone también de manifiesto la incapacidad de la UE para generar una mayor convergencia, especialmente en aquellos problemas con un grado de europeización elevado. El porcentaje de legislación estatal y autonómica europeizada aumenta progresivamente desde 1986 hasta la actualidad, pero la delegación de poder hacia arriba, en favor de la UE, no se ha traducido en una mayor homogeneidad de las agendas legislativas, ni siquiera en aquellos sectores más europeizados, como agricultura o medio ambiente. El mayor grado de europeización de la agenda legislativa estatal, en comparación con las agendas autonómicas, pone también de manifiesto el protagonismo del gobierno central en la fase descendente, de implementación de la normativa comunitaria. No obstante, para llegar a una conclusión definitiva sobre esta cuestión, debería analizarse también la europeización de la legislación secundaria, ya que una parte importante de directivas se implementan mediante este tipo de legislación.

En este artículo argumentamos que la mayor divergencia entre las agendas autonómicas se explica en parte por las preferencias políticas, y las prioridades establecidas por los partidos políticos en el gobierno de cada CCAA. El marco competencial y la distribución de poder entre niveles de gobierno definen las reglas del juego y limitan la capacidad de los gobiernos para regular sobre cuestiones concretas. No obstante, dentro de las limitaciones impuestas por el contexto institucional, cada partido político desarrolla estrategias distintas de acuerdo con sus preferencias políticas, marcando importantes diferencias respecto al resto de CCAA. Nuestros datos ponen de manifiesto que cuando coinciden en el gobierno autonómico partidos políticos cercanos desde un punto de vista ideológico, las agendas legislativas autonómicas son más parecidas. Las agendas catalana y andaluza se parecen más cuando los socialistas gobiernan en ambas comunidades; la agenda catalana y la del gobierno central 
son también más parecidas cuando en Cataluña gobierna el PSC y en el Estado el PSOE, y en Cataluña y el País Vasco se legisla también sobre cuestiones similares cuando gobiernan partidos nacionalistas. Del mismo modo, las diferencias entre CCAA en la priorización de problemas muy europeizados se explican por las preferencias de los partidos que gobiernan en cada una de estas comunidades. La UE determina el contenido de una parte importante de regulación, especialmente en aquellos sectores vinculados con el mercado único y el medio ambiente, pero las CCAA mantienen cierto margen de maniobra para decidir cuándo regulan sobre cuestiones concretas, de acuerdo con sus preferencias políticas.

\section{REFERENCIAS BIBLIOGRÁFICAS Y DOCUMENTALES}

Adler, E.S. y Wilkerson, J. (2008), “Intended Consequences? Jurisdictional Reform and Issue Control in the US House of Representatives", Legislative Studies Quarterly, 33: 85-114.

Aguilar, S. (1996), “La Europeización de la Política Medioambiental: La Tensión NorteSur en la Unión Europea”, Política y Sociedad, 1(23): 111-120.

Aja, E. (2003), El Estado Autonómico. Madrid: Alianza.

Baumgartner, F. y Jones, B.D. (1993), Agendas and Instability in American Politics. Chicago: University of Chicago Press.

Baumgartner, F.R., y Mahoney, C. (2008), “The Two Faces of Framing: Individual-Level Framing and Collective Issue-Definition in the EU", European Union Politics, 9(3): 435-449.

Blomquist, D. (1981), Elections and the Mass Media. Washington, DC: American Political Science Association.

Blais, A., Blake, D. y Dion, S. (1993), “Do parties make a Difference? Parties and the Size of Government in Liberal Democracies", American Journal of Political Science, 37(1): 40-62.

Boix, C. (2000), "Partisan Governments, the International Economy, and Macroeconomic Policies in Advanced Nations, 1960-1993", World Politics, 53: 38-73.

Borghetto, E. y Franchino, F. (2010), "The Role of Subnational Authorities in the Implementation of EU Directives", Journal of European Public Policy, 17(6): 759-780.

Börzel, T. (2002), States and Regions in the European Union. Institutional Adaptation in Germany and Spain. Cambridge: Cambridge University Press.

Brouard, S., Costa, O. y Köning T., eds. (2011), Delors' Myth : the scope and impact of EU on law production. Nueva York: Jon Springer.

Brouard, S., Wilkerson, J., Baumgartner, F.R., Timmermans, A., Bevan, S., Breeman, G., Breunig, Ch., Chaqués, L., Green-Pedersen, Ch., Jennings, W., Peter, J., Jones, B. D. y Lowery, D. (2009), "Comparer les Productions Législatives: Enjeux et Méthodes", Revue International de Politique Comparée, 16(3): 381-404.

Budge, I. y Hofferbert, R. I. (1990), "Mandates and Policy Outputs: US Party Platforms and Federal Expenditures", American Political Science Review, 84(1): 111-131.

Casademunt, A. (2001), "Política i gestió de residus a Catalunya: rendiments desiguals i molts interrogants de futur”, en R. Gomà y J. Subirats, eds., Govern i polítiques

128 públiques a Catalunya: 1980-2000. Barcelona: Edicions Universitat de Barcelona. 
Chaqués, L. y Palau, A.M. (2011), “Are Spanish policy-makers responding to citizens' priorities?", West European Politics. Artículo a publicarse en julio de 2011.

Chaqués, L., Palau, A. M., Muñoz, L. y Wilkerson, J.D. (2008), “Comparing Governmental Agendas: Evolution of the Prioritization of Issues in the USA and Spain". IBEI Working Papers. Barcelona: IBEI. En línea: < http://www.ibei.org/images/stories/papers/WP_IBEI_14.pdf > (Consulta: 7 junio 2011)

Closa, C., ed., (2001), La europeización del sistema político español. Madrid: Itsmo.

Colomer, J. (1995), La Política en Europa: Introducción a las instituciones de quince países. Barcelona: Ariel.

De Miguel, J. (2002), "Leyes de CCAA sobre Universidad”, Gestión y Análisis de Políticas Públicas, 25: 131-153.

Delgado, I. (2011), Alcanzado el equilibrio. El acceso y la presencia de las mujeres en los legislativos. Valencia: Tirant lo Blanch.

DiMaggio, P.J. y Powell, W. (1983), "The iron cage revisited: Institutional isomorphism and collective rationality in organizational fields", American Sociological Review, 48: $147-60$.

Dolowitz, D.P. y Marsh, D. (1996), “Who Learns What from Whom: a Review of the Policy Transfer Literature”, Political Studies, XLIV: 343-357.

Green-Pedersen, Ch. (2006), "Long-term Changes in Danish Party Politics: The Rise and Importance of Issue Competition", Scandinavian Political Studies, 29(3): 219235.

Gunther, R. y Montero, J.R. (2009), The Politics of Spain. Cambridge: Cambridge University Press.

Hall, P. (1993), "Policy Paradigms, Social Learning and the State: The Case of Economic Policy-Making in Britain", Comparative Politics, 25: 275-296.

Hall, P. and Taylor, R. (1996), "Political science and the three new institutionalisms", Political Studies, 44: 936-957.

Holzinger, K. y Knill, C. (2005), "Causes and conditions of cross-national policy convergence", Journal of European Public Policy, 12(5): 775-796.

Hooghe, L., Gary, M. y Schakel, A.H. (2010), The Rise of Regional Authority: A comparative study of 42 democracies (1950-2006). Londres: Routledge.

Jones, B.D. y Baumgartner, F.R. (2005), The Politics of Attention. Chicago: University of Chicago Press.

Klingemann, H.D., Hofferbert, R.I., y Budge, I. (1994), Parties, policies and democracy. Boulder: Westview Press.

Linz, J., y Stepan, A. (2006), “The paradigmatic case of Reforma Pactada-Ruptura Pactada: Spain”, en J. Linz y A. Stepan, eds., Problems of Democratic Transition and Consolidation: Southern Europe, South America and Post-Communist Europe. Baltimore: Johns Hopkins University Press.

Montilla, J. (2005), Derecho de la Unión Europea y Comunidades Autónomas. Madrid: Centro de Estudios Políticos y Constitucionales.

Morata, F. (1992), "Institucionalización y rendimiento político del Estado Autonómico", Revista de Estudios Políticos, 76: 255-297.

Ordóñez, D. (1995), "La Recepción del Derecho Comunitario europeo en el ordenamiento español”, Noticias de la Unión Europea, 125: 99-113. 
Palau, A. y Chaqués, L. (2011) “The Europeanization of law-making activities in Spain”, en Brouard, S., Costa, O. y Köning T., eds., Delors' Myth : the scope and impact of EU on law production. Nueva York: Jon Springer.

Porras, A. (2002), "La actividad legislativa de los Parlamentos autonómicos 19802000: agenda legislativa y mapa normativo", en J. Subirats y R. Gallego, eds., Veinte Años de Autonomías en España. Madrid: Centro de Investigaciones Sociológicas.

Requejo, F. y Caminal, M. (2010), Political Liberalism and Plurinational Democracies. Londres: Routledge.

Schmidt, M.G. (1996), "When parties matter: a review of the possibilities and limits of partisan influence on public policy", European Journal of Political Research, 30: 155-183.

Steinmo, S., Thelen, K. y Longstreth, F. (1992), Structuring Politics: Historical Institutionalism in Comparative Analysis. Nueva York: Cambridge University Press.

Subirats, J. y Gallego, R., eds. (2002), Veinte años de autonomías en España: Leyes, políticas públicas, instituciones y opinión pública. Madrid: Centro de Investigaciones Sociológicas.

Recibido: 5 de marzo de 2011

Aceptado: 13 de mayo de 2011 